\title{
WHEN INCUMBENTS CHANGE THEIR MIND: FRAMING STRATEGIC REORIENTATION IN EMERGING FIELDS
}

\author{
CHRISTINA M. BIDMON \\ Católica Lisbon School of Business \& Economics \\ Palma de Cima, 1649-023 Lisbon, Portugal \\ RENÉ BOHNSACK \\ Católica Lisbon School of Business \& Economics, Portugal
}

\section{INTRODUCTION}

In the fields that emerge around novel technologies, the question of when a novel technology is ready to break through is typically subject to lively debate. How an actor frames the new technology's potential and its own plans to engage in it can become an important source of agency, because it guide meaning-making and prospective action in other actors (Purdy, Ansari, \& Gray, 2017). A particularly interesting case in this regard are the framing efforts of incumbents, for whom the breakthrough of a new technology implies a strategic dilemma. On the one hand, they have an incentive to temper expectations about the novel technology to protect their current operations. On the other hand, they have incentive to stir expectations to legitimize investments they make into the new technology. Given also the multiple, and potentially conflicting, interests of incumbents' various stakeholders, the communication about the plans to engage in an emerging field can become a delicate issue (Fiss \& Zajac, 2006; Rhee \& Fiss, 2014).

In this study, we set out to investigate how incumbents frame the prospects of a new technology to external constituents. Our empirical setting to investigate this question is the emerging field around electric mobility in Germany. Based on 328 CEO interviews in the German press and 125 letters to shareholders, we study how the five biggest German car manufacturers communicated about electric mobility in the 25 years from 1993 to 2017 . Our findings reveal that, within the gradual shift from opposition to support, the incumbents continued to both stir and temper expectations about electric mobility. Drawing on recent literature on temporal framing (Nadkarni, Pan, \& Chen, 2018) and strategic ambiguity (e.g., Sillince, Jarzabkowski, \& Shaw, 2012), we elaborate on temporal maneuvering as a mechanism that enabled them to do so. We describe three maneuvering tactics that underlie this mechanism and discuss how the car manufacturers used them to retain ambiguity about the proximity of a technology shift and their own engagement in the emerging field.

Our study contributes to current work that suggests that the construction of ambiguity is a mechanism to cope with the ambiguity an actor meets in the context it is embedded in (Denis, Dompierre, Langley, \& Rouleau, 2010; Jarzabkowski, Sillince, \& Shaw, 2010; Sillince et al., 2012). Whereas such work has paid attention to the rhetoric construction of ambiguity, it has not yet considered which role the strategic use of time and temporal distance play herein. Our study also contributes to the literature on temporal framing, or more broadly, strategic framing, which has shown that actors' frames are likely to change over time (e.g., Litrico \& David, 2017). Here, the 
notion of temporal maneuvering helps to assess how timing-related cues support an actor in the gradual preparation and explanation of frame changes to external constituents.

\section{THEORETICAL BACKGROUND}

Research has long recognized the critical role of CEOs' verbal and textual communication in constructing meaning about organizational changes for internal and external constituents (Mintzberg, 1973). A central aspect in the communication about changes is time, or timing. In order to consider how the German car manufacturers framed the prospects of EVs and their own actions, we build on the concepts of (i) temporal framing, and (ii) strategic ambiguity.

\section{Temporal framing}

Frames are interpretive lenses that actors strategically evoke through their communication in order to shape meaning-making in others and mobilize support (e.g., Cornelissen \& Werner, 2014). To frame is to "select some aspects of a perceived reality and make them more salient in a communicating text, in such a way as to promote a particular problem definition, causal interpretation, moral evaluation, and/or treatment recommendation" (Entman, 1993: 52). The term "temporal framing", however, is more specifically associated with the provision of time-related cues in an act of speech or text corpus. Recently, Nadkarni et al. (2018) have conceptualized temporal framing as a three-dimensional construct consisting in (i) temporal vagueness (lack of clarity and completeness; "soon, long-term" vs. "2010, five years"), (ii) temporal distance (length of an action timeline; "one day, one week" vs. "five years, a decade"), and (iii) frequency (repetition of vagueness and distance cues). They base these dimensions in inter-temporal choice theory, which holds that the more vague or distant a future action is presented, the lower the sense of urgency and motivation for action that is invoked in an audience (Berns, Laibson, \& Loewenstein, 2007; Loewenstein, 1988).

\section{Strategic ambiguity}

Ambiguity exists when there is a "state of having many ways of thinking about the same circumstances or phenomena" (Feldman, 1989: 5). Scholars disagree on how such a state can arise. Some see ambiguity as a feature intrinsic to contexts that are risky or uncertain and something that ought to be reduced because it impedes planning and decision-making (Cohen, March, \& Olsen, 1972; Eisenhardt \& Zbaracki, 1992). In turn, others see ambiguity as a state that is rhetorically constructed and can be political necessity (Sillince, Jarzabkowski, \& Shaw, 2012; Eisenberg, 1984) and might even enable, not hamper, action (Gioia, Nag, \& Corley, 2012; Jarzabkowski et al., 2010; Sillince et al., 2012; Vaara, 2007). Summarizing, research on strategic ambiguity has pointed out that (i) actors can exploit ambiguity where they encounter it as a condition of the context they are embedded in, and (ii) also actively construct ambiguous meanings to harness and maintain strategic ambiguity as a resource.

\section{EMPIRICAL SETTING AND DATA ANALYSIS}


To study incumbents' strategic framing efforts of a new technology, we use the potential technology shift from the combustion engine to the electric engine. We limited our study to a national setting, Germany, to construct a richer account of how incumbents took part in the local discourse, which is likely to be closely entangled with issues of national regulation, infrastructure, or user preferences. The German setting, in particular, seemed suitable because the country is home to several large car manufacturers such as Volkswagen, BMW, Daimler, Porsche, and Audi. We focused on the period between 1993 and 2017 because it demarcates the period from the first national field test with electric vehicles to the point where all five car manufacturers had publicly announced to electrify their product portfolio and "go all-in" with EVs. To obtain a contemporary, unfiltered picture of how the car manufacturers saw the current maturity and future prospects of EVs over the 25-year period, we relied on statements by their CEOs. A key data source were (i) letters to shareholders in the 125 reports the five companies issued over the 25 years, and (ii) interviews with CEOs directed at the wider public. To obtain the interviews, we performed a fulltext search in the five most widely circulated daily newspapers (excluding yellow press) in Germany, five weekly newspapers, three business magazines, and three industry magazines. After eliminating those interviews that clearly focused on issues irrelevant to our study, such as CEO compensation or Formula 1, 328 interviews remained for further analysis.

In a first step, we extracted statements related to electric mobility and categorized them into whether they referred to the car manufacturers' own plans or the technology in general, and whether they referred to the present or the future. We used points of discontinuity in the incumbents' framing efforts to temporally bracket (Langley, 1999) phases of major frame change. In total, we identified three phases in which the car manufacturers gradually moved from opposing electric mobility to supporting electric mobility. In a second round of open coding, we then assessed how the car manufacturers used time-related statements to explain their gradual reorientation. We pooled codes together according to their similarity (Corley \& Gioia, 2004; Gioia, Corley, \& Hamilton, 2013). We refer to the resulting categories as "temporal maneuvering tactics".

\section{FINDINGS}

Various developments in the mobility sector such as the emergence of alternative propulsion systems, car sharing, or autonomous driving challenged the car manufacturers' confidence in making projections on future market developments. As Dieter Zetsche stated in 2016 when questioned on Daimler's future course of action: "We are creating conditions for developments that we do not even know yet. That is the point: Nobody can plan what is going to happen." Specifically with regard to EVs, he remarked: "With e-mobility it is a little like a ketchup bottle. You know that something is coming, but not when or how much." Yet, over the course of the 25 years, the car manufacturers clearly moved from a rather opposing, sceptic stand toward EVs to a more optimistic, supporting stand. We differentiate between three phases marking this gradual reorientation: In the phase from 1993 to 2007, the dominant framing efforts can be described with the catchphrase "The technology is immature, we experiment". Over the years from 2007 to 2014, framing efforts slowly shifted to "The technology is still inferior, we invest in improvements". In the years from 2014 to 2017 , the framing efforts then started to sound like "The technology is ready, we go all-in". 
At first glance, these framing efforts do not seem too ambiguous. It seemed the car manufacturers adjusted their projections in line with factors such as maturity of the technology, market demand, and regulation. Yet, on a more fine-grained level, they also juggled with competing frames. For example, only in the very early years of phase 1 did statements completely deny the future potential of electric engines. Similarly, the car manufacturers rarely completely spoke out against combustion engines. Even in the light of the Dieselgate scandal, the maximum turn against this technology was marked by statements that, at some point, the electric engine is likely to replace the combustion engine.

What we observed by studying the framing efforts of the German car manufacturers is the continuous struggle of an actor group to satisfy the demands of divergent constituents while trying to retain maximal flexibility to adjust to the ongoing dynamics. In handling this struggle, the car manufacturers seemed to frame the potential turn to EVs as both temporally distal and temporally proximal, i.e. they shifted between stirring and tempering expectations in the audience they were addressing. The basic pattern that emerged from the data was that time-related statements were used in a distinct way to offset each other: Framing electric mobility as unattractive in the present was frequently softened by stirring expectations about its future potential. In turn, framing electric mobility as attractive in the present was frequently softened by tempering expectations about its future potential. Such "temporal maneuvering" was underpinned by a threefold set of tactics: (i) putting developments into perspective, (ii) invoking risk, and (iii) mobilizing learnings.

\section{Maneuvering tactic 1: Putting developments into perspective}

A first maneuvering tactic was to put events and actions into perspective. In order to stir expectations, the car manufacturers emphasized that the impact on the future of something that might seem like a small step in the present must not be underestimated. For instance, the first EVs they eventually brought to market were framed as "the beginning of a new era", and their corporate change programs as the "biggest turnarounds in corporate history" or "just the beginning". In turn, when the purpose was to temper expectations, the car manufacturers downplayed the future impact of something that might seem like a big step in the present. For this purpose, the first hybrids and EVs were framed as "not the solution to everything" and the initiation of corporate changes programs turned into " 5 kilometers of a marathon". Putting developments into perspective assigned impact and scope to developments. It served as a very direct way of guiding meaning-making and offering an alternative interpretation to an audience.

\section{Maneuvering tactic 2: Invoking risk}

A second maneuvering tactic was to invoke risk. In order to stir expectations, for instance, the car manufacturers leveraged on the necessity to produce and sell more EVs as critical to avoid penalties or that, without investing in EVs, it was not a given "that the car manufacturers of today will be the car manufacturers of tomorrow". Invoking risk in this manner was mainly used when they were challenged on actions, such as investments, they had either taken or were planning to take. However, the tactic of invoking risk also served to legitimize inaction and temper expectations in an audience. This became manifest mostly in doubting whether, or when, EVs 
could be produced at a profitable margin and in questioning future market demand. Invoking risk was not a direct way of guiding meaning-making in an audience, but rather aimed at casting doubt and caution.

\section{Maneuvering tactic 3: Mobilizing learnings}

A third tactic was the mobilization of past learnings, or history. In order to stir expectations, for instance, the car manufacturers frequently referred to technology shifts in other sectors such as the transition from mechanic to electric typewriters, horse carriages to automobile, steam to diesel trains, or mobile to smart phone. Whereas they often mobilized such examples to stir expectations on the high speed at which change could potentially occur, they also employed these examples to emphasize that all these past technology shifts had only led to a redistribution, not a loss of jobs. In turn, the past was also mobilized to temper expectations on the speed of change. Here, the car manufacturers mostly referenced their own experiences with models that had failed to meet sufficient customer demand. Frequent examples that were mobilized for this sake were early attempts with eco-cars in the late 1990s such as Volkswagen's 3-liter-Lupo or Audi's Eco-A2. In its effect, mobilizing past learnings was similar to invoking risk. It aimed at casting doubt about how to interpret developments. It was different from invoking risk, however, in that the reference point was the past, not the future.

The three maneuvering tactics each have a temporal element; putting developments into perspective refers to framing present developments, invoking risk refers to events that might take place in the future, and mobilizing learnings refers to past experiences, or history. In their effect, however, all three maneuvering tactics work to either stir or temper expectations about the future and the own engagement in the field. They paint a picture of how the car manufacturers were able to continuously bounce back and forth between the demands of different audiences. Depending on whether journalists or a specific situation required them to defend their action versus inaction, low versus high investments, or tentative versus full support of EVs, the three tactics allowed them to quickly adjust. Arguably, temporal maneuvering thereby supported the maintenance of strategic ambiguity about the proximity of a potential technology shift.

\section{DISCUSSION AND CONCLUSION}

As other scholars have argued, tactics or practices that aim at retaining ambiguity try to convey decisions in a manner that make them acceptable to a variety of stakeholders so that they can each assert their own interests to them (Denis et al., 2010; Eisenberg, 1984; Jarzabkowski et al., 2010; Sillince et al., 2012). Temporal maneuvering does fulfill this criterion. By putting developments into perspective, invoking future risk, and mobilizing past learnings the car manufacturers arguably provided different audiences the possibility to identify themselves with what they had stated.

We define temporal maneuvering as having two identifying characteristics: First, it is a mechanism that intentionally offers alternative futures so as to retain strategic ambiguity about the exact timing of events and actions. As such, temporal maneuvering is similar to the concept of temporal framing (Nadkarni et al., 2018) in that it refers to the intentional sending of linguistic cues 
in public forums to evoke an effect in an audience. However, it is different from temporal framing in that it does not aim to evoke a specific interpretation of importance and urgency of action. On the contrary, it aims at retaining ambiguity about action timelines. Second, temporal maneuvering is a mechanism that hinges on the presence of ambiguity in the contexts where it is applied. In other words, it is a mechanism that works in settings where there indeed is room for interpretation about long-term developments that can be exploited. The potential technology shift to the EV arguably provided the German car manufacturers with such a context. It seems plausible that temporal maneuvering might also occur in other settings where actors have to communicatively signal, prepare, and handle the phase-out and phase-in of an old versus a new technology. Here, it would be interesting for future research to compare differences in the use of maneuvering tactics. In turn, it also seems worthwhile to investigate whether, or in which forms, temporal maneuvering exists in other, less ambiguous, contexts where word can quickly turn into action and it is easy for an audience to hold actors accountable for projections. Another area for future research lies in the further assessment of the effect which temporal maneuvering evokes in an audience. Specifically, the maneuvering tactics identified in this study might help to address an issue that has, according to Gray et al. (2015), not yet received much attention; namely, how actors can keep up a plurality of frames simultaneously and thereby contribute to ambiguity in an organization or field.

In general, there seems to lie much potential in the connection of studies on the strategic use of time to recent work on the construction of ambiguity (Denis et al., 2010; Sillince et al., 2012) and the microprocesses of frame change (Gray et al., 2015; Purdy et al., 2017; Litrico \& David, 2017). Because timelines and expectations are an important source of agency, insights into the communicative practices of the actors engaged in a technology shift are ultimately also important for understanding the formation of meaning and action in emerging fields.

REFERENCES AVAILABLE FROM THE AUTHORS 